\title{
Association of the wild-type A/A genotype of MBL2 codon 54 with asthma in a North Indian population
}

\author{
Niti Birbian ${ }^{\mathrm{a}}$, Jagtar Singh ${ }^{\mathrm{a}, *}$, Surinder Kumar Jindal ${ }^{\mathrm{b}}$, Amit Joshi ${ }^{\mathrm{c}}$, Navneet Batra ${ }^{\mathrm{d}}$ and Neha Singla ${ }^{\mathrm{a}}$ \\ ${ }^{a}$ Department of Biotechnology, Panjab University, Chandigarh, India \\ ${ }^{\mathrm{b}}$ Department of Pulmonary Medicine, PGIMER, Chandigarh, India \\ ${ }^{\mathrm{c}}$ Department of Biotechnology, S.G.G.S. College, Chandigarh, India \\ ${ }^{\mathrm{d}}$ Department of Biotechnology, G.G.D.S.D. College, Chandigarh, India
}

\begin{abstract}
Background: High serum MBL level as well as polymorphisms in the mannose-binding lectin 2 (MBL2) gene resulting in MBL deficiency are involved in the mechanism of a number of non-infectious diseases such as asthma, conferring either risk or protection in different population studies. MBL being the first reactant of the MBL pathway is also a major determinant of the fate of the anaphylatoxins such as $\mathrm{C} 3 \mathrm{a}$ and $\mathrm{C} 5 \mathrm{a}$, which are also pro-inflammatory mediators. The MBL2 gene polymorphisms thus control the serum levels of MBL as well as C3a and C5a.

Objective: This is the first case-control study conducted in India, investigating the role of MBL2 codon 54 A/B polymorphism in asthma pathogenesis.

Methods: A case-control study was performed with a total of 992 adult subjects, including 410 adult asthmatics and 582 healthy controls from regions of North India. The MBL2 codon 54 A/B polymorphism was genotyped by PCR-RFLP.

Results: Statistical analysis for the codon 54 polymorphism revealed that the wild (A) allele was significantly associated with asthma with $\mathrm{OR}=1.9,95 \% \mathrm{CI}(1.4-2.4)$, and $p<0.001$.

Conclusion: The MBL2 codon $54 \mathrm{~A} / \mathrm{B}$ polymorphism is significantly associated with asthma and its phenotypic traits as the wild (A/A) genotype confers a significant risk towards the disease in the studied North Indian population.
\end{abstract}

Keywords: Asthma, mannose-binding lectin 2 (MBL2), anaphylatoxins, C3a, C5a, MBL2 codon 54 A/B polymorphism, North Indian population

\section{Introduction}

Asthma is a complex genetic inflammatory disorder of the lungs, characterized by acute bronchial hyper responsiveness (BHR), shortness of breath (SOB), chest tightness, cough and sputum production in response to a variety of external stimuli [36], with or without atopy [26].

Mannose-binding lectin (MBL), an active component of the innate immune system, is a Ca-dependent

* Corresponding author: Dr. Jagtar Singh, Department of Biotechnology, Panjab University, Chandigarh, India. Tel.: +91 172253 4065; Fax: +91 172 2541407; E-mail: jagtar@rediffmail.com. serum protein synthesized by the hepatocytes in the liver [6]. MBL is a "pattern recognition molecule" encoded by the MBL2 gene located at 10q11.2-q21 [17,23] and is a trimer of three identical polypeptide chains, each possessing a cysteine rich region, a collagen like region, a neck and a 'carbohydrate recognition domain' (CRD), which enables the lectin protein to recognize the mannose and $\mathrm{N}$-acetyl glucosamine moieties on the surface of a variety of pathogens including viruses, bacteria, fungi as well as protozoans [21].

While the MBL may be implicated in the microorganism destruction by the formation of a 'membrane attack complex' (MAC), it more importantly displays an opsonin effect by tagging the pathogen surface for recognition and ingestion by phagocytes via the 
mannose-binding lectin (MBL) pathway, which is one of the major pathways of the complement system [7]. Once the MBL tags the carbohydrate residue on the pathogen, it complexes with the MBL- associated serine proteases (MASPs) to form an enzyme that cleaves $\mathrm{C} 4$ into $\mathrm{C} 4 \mathrm{a}$ and $\mathrm{C} 4 \mathrm{~b}$. $\mathrm{C} 4 \mathrm{a}$ is released while $\mathrm{C} 4 \mathrm{~b}$ binds to the enzyme. $\mathrm{C} 2$ then assembles on $\mathrm{C} 4 \mathrm{~b}$ and is cleaved into $\mathrm{C} 2 \mathrm{a}$ and $\mathrm{C} 2 \mathrm{~b}$. $\mathrm{C} 2 \mathrm{~b}$ is released while $\mathrm{C} 2 \mathrm{a}$ binds to the enzyme to form a $\mathrm{C} 4 \mathrm{~b} 2 \mathrm{a}$ domain which functions as ' $\mathrm{C} 3$ convertase' that cleaves $\mathrm{C} 3$ molecules into $\mathrm{C} 3 \mathrm{a}$ and $\mathrm{C} 3 \mathrm{~b}$, where $\mathrm{C} 3 \mathrm{a}$ is released while $\mathrm{C} 3 \mathrm{~b}$ associates with $\mathrm{C} 3$ convertase to form ' $\mathrm{C} 5$ convertase' which then cleaves $\mathrm{C} 5$ to release $\mathrm{C} 5 \mathrm{a}$ [18].

The anaphylatoxins $\mathrm{C} 3 \mathrm{a}$ and $\mathrm{C} 5 \mathrm{a}$ liberated as $\mathrm{MBL}$ pathway byproducts are potent pro-inflammatory mediators capable of causing smooth muscle contraction. Also, C3a and C5a are chemoattractants which recruit a variety of inflammatory cells such as neutrophils, eosinophils, monocytes and T-lymphocytes and result in tissue damage [30]. Moreover, C3a and C5a molecules have been established as potential effectors in asthma and allergic inflammatory disorders [13].

Serum MBL levels are influenced by polymorphisms in the MBL2 gene, where the three low producing SNPs in exon 1, at codon 52 resulting in substitutions of CGT $\rightarrow$ TGT (Arg $\rightarrow$ Cys), codon 54 GGC $\rightarrow$ GAC (Gly $\rightarrow$ Asp) and codon 57 GGA $\rightarrow$ GAA (Gly $\rightarrow$ Glu), alter the structural assembly of the MBL protein giving rise to $\mathrm{A} / \mathrm{D}, \mathrm{A} / \mathrm{B}$ and $\mathrm{A} / \mathrm{C}$ polymorphisms respectively $[14$, $22,31]$.

Both MBL deficiencies as well as over secretions by the liver in blood have been associated with increased risk, severity, infections and autoimmune disorders [9, 24].

In murine models, MBL insufficiency has shown to cause hyperresponsiveness during fungal asthma [5]. MBL2 variant alleles have also been associated with susceptibility towards asthma in children with pneumonia infection [3]. A Turkish study has suggested implication of MBL in asthmatic children [4] and these findings are also supported by a Chinese study on asthmatic children where MBL2 codon 54 SNP has been associated with asthma [34]. Two Indian studies have demonstrated the role of MBL 1011G/A, SP-D 341 T/C and MBL 1011G/A polymorphisms in atopic asthma, respectively [11,32].

Although a few studies have reported no association between MBL2 polymorphisms and atopic asthma in adults in a Finnish population [15] and in a Japanese study [37], increased MBL serum levels have been implicated in a wide range of non-infectious autoim- mune diseases such as systemic lupus erythematosus (SLE), rheumatoid arthritis, Type-I diabetes, Crohn's disease, cystic fibrosis, sepsis, lung injury, myocardial ischemia-reperfusion as well as asthma $[8,16,20,27,28$, 35]. Increased MBL levels have also been associated with infectious diseases such as tuberculosis (TB) and leprosy [2,29], and it has been suggested that low MBL levels confer protection against TB [12].

Moreover, it has been observed that post allergen challenge, the anaphylatoxin $\mathrm{C} 3 \mathrm{a}$, which is otherwise produced as a byproduct of the MBL pathway, is present in elevated levels in the broncholaveolar lavage (BAL) fluid of asthma patients $[1,10,25,38]$ as well as in the plasma [38], highlighting the role of C3a in MBL pathway. In two separate studies conducted in the USA, it has been observed that the deletion of $\mathrm{C} 3$ a receptor in murine models of asthma protects against lung damage observed during allergen challenge during asthma attack, thereby signifying the role of C3a in asthma [1, 33]. Another study has suggested that the complement system not only plays an important role in innate immunity, but if uncontrolled, contributes to amplified inflammation [19].

The present study hypothesizes that the functional MBL2 codon 54 wild A allele results in high serum MBL level that leads to a greater availability of MBL for participation in the lectin pathway and hence result in an enhanced complement activation which cause asthma. On the other hand, the MBL2 exon 1 codon $54 \mathrm{~A} / \mathrm{B}$ polymorphism results in low MBL production, resulting in a lesser participation in the MBL pathway by lowering the production of the first metabolite of the cascade itself, thereby resulting in a reduced production of anaphylatoxins such as $\mathrm{C} 3 \mathrm{a}$ and $\mathrm{C} 5 \mathrm{a}$, which are otherwise mediators of inflammation and asthma.

\section{Methods}

Ethical Clearance for conducting the study on human blood samples was granted by the "Ethics Committee, PGIMER, Chandigarh". The study was conducted strictly in accordance with the ethical guidelines for bio-medical research on human subjects proposed by the "Central Ethics Committee on Human Research (CECHR) ICMR-2000" and of those contained in the "Declaration of Helsinki". The selection of asthma patients was based on physician's diagnosis. However, only the patients fulfilling the criteria of GINA (Global Initiative for Asthma) guidelines for diagnosis of bronchial asthma were recruited in the study. 
This is the first case-control study conducted in India evaluating the role of MBL2 exon1 codon $54 \mathrm{~A} / \mathrm{B}$ polymorphism in asthma pathogenesis by recruiting a total of 992 adult subjects. The patients were recruited from different states of North India such as Punjab, Haryana, Chandigarh, Uttar Pradesh, Himachal Pradesh, Uttaranchal, Jammu and Kashmir, Rajasthan and New Delhi. A total of 410 asthma patients visiting the Out Patient Department (OPD), Pulmonary Medicine, Post Graduate Institute of Medical Education and Research (PGIMER), Chandigarh, were enrolled in the study on the basis of physicians' diagnosis and spirometry test results. Out of the total, 323 subjects were asthma patients with allergic rhinitis. No ABPA (Allergic Bronchopulmonary Aspergillosis) patients were taken in the study. Informed Consent was duly obtained in written from the asthma patients participating in the study, and a detailed proforma of the asthma patients with a complete questionnaire regarding the clinical symptoms of the disease, i.e. wheeze/whistling, cough, shortness of breath (SOB), allergy, early morning or night symptoms, along with spirometry tests, etc., was assessed. Complete information of the patient regarding name, age, sex, history of the disease, occupation, etc., was taken into account (Table 1). Asthma patients with history of any other pulmonary ailment such as tuberculosis, Chronic Obstructive Pulmonary Disease (COPD), bronchitis, etc., were excluded from the study.

A total of 582 normal, healthy controls, with no history of asthma or allergic diseases or any other comorbid illness were inducted in the study. Some of the healthy volunteers were blood donors at various blood donation camps, educational institutes, employee groups. Care was taken that the control subjects did not have any of the patient conditions in the past. Any subject having a first degree relative with asthma or allergy has not been recruited as a control in the present study. Not only the respiratory or allergic skin disorders, any subject with other diseases such as diabetes, high blood pressure, etc., or with drinking and smoking habits have also not been included as controls in the study. Each control was first enquired for all of the above conditions at the time of taking their written informed consent and before the collection of blood samples.

Blood samples were collected in EDTA coated vials, and stored at $-80^{\circ} \mathrm{C}$ until genomic DNA extraction was done. Genomic DNA was isolated from the thawed blood samples by the Sodium Saline Citrate Buffer Method, and checked for DNA on $0.8 \%$ agarose gel by electrophoresis.
Table 1

Characteristics of the study population

\begin{tabular}{|c|c|c|}
\hline & $\begin{array}{c}\text { Asthma patients } \\
410(\%)\end{array}$ & $\begin{array}{l}\text { Controls } \\
582(\%)\end{array}$ \\
\hline \multicolumn{3}{|l|}{ Sex } \\
\hline Males & $183(44.6)$ & $351(60.3)$ \\
\hline Females & $227(55.4)$ & $231(39.7)$ \\
\hline Age & $38.1 \pm 16.2$ & $41.9 \pm 16.6$ \\
\hline Allergic rhinitis & $323(78.8)$ & 0 \\
\hline No rhinitis & $87(21.2)$ & 582 \\
\hline \multicolumn{3}{|l|}{ Allergic to atleast } \\
\hline 2 provoking factors & $366(89.3)$ & 0 \\
\hline Non-allergic & $44(10.7)$ & 582 \\
\hline Non-Smoker & $345(84.1)$ & 582 \\
\hline Ever-Smoker & $65(15.9)$ & 0 \\
\hline \multicolumn{3}{|l|}{ Spirometry data* } \\
\hline FVC observed & $2.56 \pm 0.96$ & 0 \\
\hline FVC predicted & $3.19 \pm 0.73$ & 0 \\
\hline $\mathrm{FEV}_{1}$ observed & $1.94 \pm 0.82$ & 0 \\
\hline $\mathrm{FEV}_{1}$ Predicted & $2.68 \pm 0.77$ & 0 \\
\hline $\mathrm{FEV}_{1} / \mathrm{FVC}$ observed & $75.00 \pm 13.71$ & 0 \\
\hline $\mathrm{FEV}_{1} / \mathrm{FVC}$ predicted & $83.12 \pm 5.84$ & 0 \\
\hline
\end{tabular}

FVC, Forced Vital Capacity; FEV 1 , Forced Expiratory Volume in 1 second.

* Spirometry test was conducted for 190 asthma patients.

The amplification of the MBL2 codon 54 was done with forward 5'-AGTCGACCCAGATTGTAGGACA GAG-3' and reverse 5'-AGGATCCAGGCAGTTTCC TCTGGAAGG-3' primers [14]. PCR was carried out in a thermal cycler, in a total volume of $25 \mu \mathrm{l}$ containing: 10X PCR Buffer, $3 \mathrm{mM} \mathrm{MgCl}_{2}, 1 \mathrm{mg} / \mathrm{ml} \mathrm{nu}-$ clease free BSA, 50 pmol of each primer, $10 \mathrm{mM}$ of each dNTP, $0.125 \mathrm{U}$ Taq polymerase and $2 \mu$ l genomic DNA. The PCR conditions were: initial denaturation at $94^{\circ} \mathrm{C}$ for $5 \mathrm{~min}$, followed by 35 cycles at $94^{\circ} \mathrm{C}$ for $30 \mathrm{sec}, 60^{\circ} \mathrm{C}$ for $1 \mathrm{~min}, 72^{\circ} \mathrm{C}$ for $1 \mathrm{~min}$, and final extension step at $72^{\circ} \mathrm{C}$ for $10 \mathrm{~min}$. A 349-bp PCR product was observed as a parent band by electrophoresis on $2 \%$ agarose gels stained with ethidium bromide and visualized by UV transillumination. Alleles A and B were detected using 5U Ban I restriction digestion of the 349-bp fragment. Ban I cleaves the wild allele A into two fragments of $260 \mathrm{bp}$ and $89 \mathrm{bp}$ while leaving the mutant allele B uncut as 349 bp, while heterozygous A/B genotype is observed as 349, 260 and 89 bp bands in a single lane (Fig. 1).

The European Molecular Genetics Quality Network (EMQN) good practice guidelines have been followed. A few PCR vials with all the PCR contents except the DNA, were also included per PCR batch as "negative controls". No contamination was observed and there were no "false positives". To minimize the risk of contamination, sterilized and autoclaved solutions and equipment were used during DNA isolation. The ingredients for PCR were well stored at $-20^{\circ} \mathrm{C}$ and were 
Table 2

Distribution of MBL2 codon 54 genotypes and allele frequencies in asthma patients and controls

\begin{tabular}{lccccc}
\hline $\begin{array}{l}\text { Genotype } \\
\text { frequencies }\end{array}$ & $\begin{array}{c}\text { Asthma patients } \\
410(\%)\end{array}$ & $\begin{array}{c}\text { Controls } \\
582(\%)\end{array}$ & OR & $(95 \% \mathrm{CI})$ & p-value \\
\hline Genotype Frequencies & & & & & \\
B/B & $5(1.2)$ & $25(4.3)$ & & Ref $(1.0)$ & \\
A/A & $308(75.1)$ & $353(60.7)$ & 2.0 & $(1.5-2.6)$ & 0.0001 \\
A/B & $97(23.7)$ & $204(35.1)$ & 0.6 & $(0.4-0.8)$ & 0.0001 \\
A/A+A/B & $405(98.8)$ & $557(95.8)$ & 3.6 & $(1.3-10.9)$ & 0.0053 \\
Allele Frequencies & & & & & \\
B & $107(13.0)$ & $254(21.8)$ & & Ref $(1.0)$ & \\
A & $713(87.0)$ & $910(78.2)$ & 1.9 & $(1.4-2.4)$ & 0.0001 \\
\hline
\end{tabular}

A/A, Homozygous Wild; A/B, Heterozygous; B/B, Homozygous Mutant; OR, Odds Ratio.

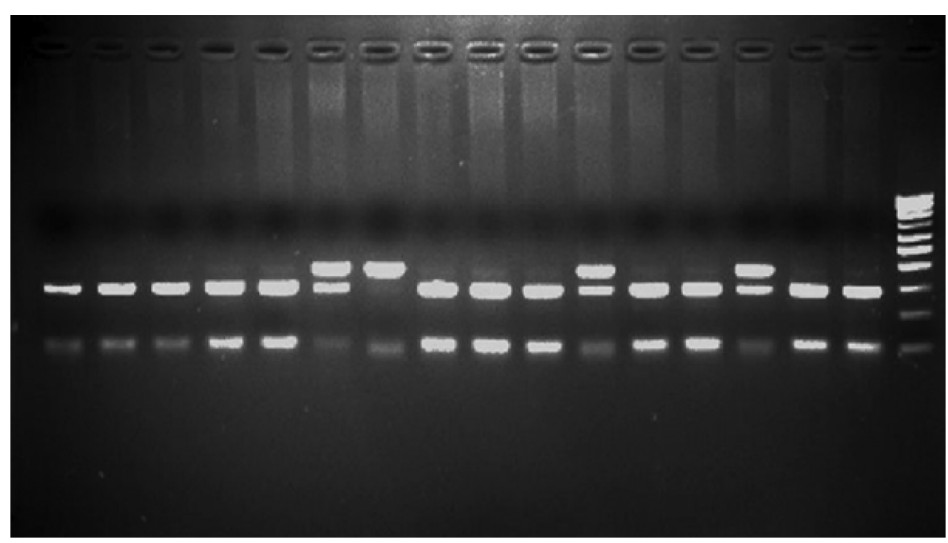

Fig. 1. PCR-RFLP products of MBL2 codon 54 A/B polymorphism on 2\% Agarose gel. Lanes 1, 2, 3, 4, 5, 8, 9, 10, 12, 13, 15, 16: Homozygous wild A/A genotype (260 and 89 bp), Lanes 6, 11, 14: Heterozygous A/B genotype (349, 260 and 89 bp), Lane 7: Homozygous mutant B/B genotype (349 bp), Lane 17: 100 bp Ladder.

thawed just before use. The patients and controls were not genotyped in separate batches but were randomly analyzed. Retyping of samples was done at random to check for the homology of results.

The genotypic as well as the allelic distribution of the MBL2 codon $54 \mathrm{~A} / \mathrm{B}$ polymorphism, between the asthmatics and control subjects, were analyzed statistically using Fisher's exact test. The data was analyzed with SPSS 17.0 software and Epi Info version 3.4.3. Statistical significance was assumed for $p<0.05$.

\section{Results}

In the present study, a total of 992 subjects, including 410 adult asthma patients and 582 adult healthy controls were genotyped for the MBL2 codon 54 A/B polymorphism. Very interesting results were observed for the polymorphism in the current study.

Statistical analysis of the results indicated that the mutant B allele was more prevalent among the con- trols $(21.8 \%)$ than in asthma patients $(13.0 \%)$ while the overall genotypic distribution of the wild allele (A) was higher among asthma patients $(87.0 \%)$ as compared to the controls (78.2\%), conferring a significant risk towards asthma as there was a positive association between asthma and the A allele with $\mathrm{OR}=1.9,95 \% \mathrm{CI}$ (1.4-2.4) and $p<0.001$ (Table 2).

The genotypic frequencies revealed that the homozygous mutant genotype (B/B) was more prevalent in control subjects $(4.3 \%)$ than in asthma patients $(1.2 \%)$. The heterozygous genotype (A/B) was more prevalent among the controls (35.1\%) as compared to the asthma patients $(23.7 \%)$ with $\mathrm{OR}=0.6,95 \% \mathrm{CI}(0.4-0.8)$ and $p<0.001$. However, it was observed that the homozygous wild genotype (A/A) was more prevalent in asthma patients $(75.1 \%)$ than in the controls $(60.7 \%)$ with $\mathrm{OR}=2.0,95 \% \mathrm{CI}(1.5-2.6)$ and $p<0.001$. Furthermore, it was observed that asthma patients with homozygous wild genotype A/A or at least one copy of the wild allele $(\mathrm{A} / \mathrm{A}+\mathrm{A} / \mathrm{B})$, were predisposed to the disease with $\mathrm{OR}=3.6,95 \% \mathrm{CI}(1.3-10.9)$ and $p=$ 0.005 (Table 2). 
Table 3

Phenotypic characteristics of the study population and MBL2 codon 54 A/B polymorphism

\begin{tabular}{|c|c|c|c|c|c|c|c|c|c|}
\hline Phenotypic traits & $\mathrm{n}$ & $\mathrm{A} / \mathrm{A}$ & $\mathrm{A} / \mathrm{B}$ & $\mathrm{B} / \mathrm{B}$ & A & B & OR & $(95 \% \mathrm{CI})$ & p-value \\
\hline \multicolumn{10}{|l|}{ Controls } \\
\hline Males & 351 & 201 & 134 & 16 & 536 & 166 & & Ref (1.00) & \\
\hline Females & 231 & 152 & 70 & 9 & 374 & 88 & & Ref (1.00) & \\
\hline \multicolumn{10}{|l|}{ Asthmatics } \\
\hline \multicolumn{10}{|l|}{ Sex } \\
\hline Males & 183 & 135 & 46 & 2 & 316 & 50 & 2.1 & $(1.4-3.2)$ & 0.001 \\
\hline Females & 227 & 173 & 51 & 3 & 397 & 57 & 1.7 & $(1.1-2.6)$ & 0.018 \\
\hline \multicolumn{10}{|l|}{ Occurrence } \\
\hline Seasonal & 282 & 216 & 64 & 2 & 316 & 50 & & Ref (1.00) & \\
\hline Throughout & 128 & 92 & 33 & 3 & 217 & 39 & 0.8 & $(0.5-1.3)$ & 0.367 \\
\hline \multicolumn{10}{|l|}{ Severity } \\
\hline Wheeze on exertion & 216 & 155 & 58 & 3 & 368 & 64 & & Ref (1.00) & \\
\hline Wheeze at rest & 194 & 153 & 39 & 2 & 345 & 43 & 1.5 & $(0.9-2.4)$ & 0.121 \\
\hline \multicolumn{10}{|l|}{ Family History } \\
\hline Family History (Nil) & 285 & 219 & 62 & 4 & 500 & 70 & & Ref (1.00) & \\
\hline Family History (+ve) & 125 & 89 & 35 & 1 & 213 & 37 & 0.8 & $(0.5-1.2)$ & 0.274 \\
\hline \multicolumn{10}{|l|}{ Smoking Status } \\
\hline Non Smoker & 345 & 253 & 88 & 4 & 594 & 96 & & Ref (1.00) & \\
\hline Ever Smoker & 65 & 55 & 9 & 1 & 119 & 11 & 2.0 & $(0.9-4.4)$ & 0.076 \\
\hline \multicolumn{10}{|l|}{ Cough } \\
\hline Cough (Nil) & 74 & 57 & 16 & 1 & 130 & 18 & & Ref (1.00) & \\
\hline Cough $(+v e)$ & 336 & 251 & 81 & 4 & 583 & 89 & 0.9 & $(0.5-1.7)$ & 0.786 \\
\hline \multicolumn{10}{|l|}{ Sputum Production } \\
\hline Sputum (Nil) & 95 & 69 & 26 & 0 & 164 & 26 & & $\operatorname{Ref}(1.00)$ & \\
\hline Sputum (+ve) & 315 & 239 & 71 & 5 & 549 & 81 & 1.2 & $(0.7-2.1)$ & 0.613 \\
\hline \multicolumn{10}{|c|}{ Pattern of Daily Symptoms } \\
\hline Morning/Night SOB & 312 & 229 & 79 & 4 & 537 & 87 & & Ref (1.00) & \\
\hline Anytime SOB & 98 & 79 & 18 & 1 & 176 & 20 & 1.5 & $(0.8-2.8)$ & 0.191 \\
\hline \multicolumn{10}{|l|}{ Rhinitis } \\
\hline Rhinitis (Nil) & 87 & 62 & 22 & 3 & 146 & 28 & & Ref (1.00) & \\
\hline Males & 36 & 27 & 8 & 1 & 62 & 10 & & Ref (1.00) & \\
\hline Females & 51 & 35 & 14 & 2 & 84 & 18 & & Ref (1.00) & \\
\hline Rhinitis(+ve) & 323 & 246 & 75 & 2 & 567 & 79 & 1.3 & $(0.7-2.3)$ & 0.424 \\
\hline Males & 147 & 108 & 38 & 1 & 254 & 40 & 0.9 & $(0.4-2.3)$ & 0.980 \\
\hline Females & 176 & 138 & 37 & 1 & 313 & 39 & 1.7 & $(0.8-3.5)$ & 0.208 \\
\hline \multicolumn{10}{|l|}{ Allergy } \\
\hline Allergy (Nil) & 44 & 30 & 14 & 0 & 74 & 14 & & Ref (1.00) & \\
\hline Males & 19 & 15 & 4 & 0 & 34 & 4 & & Ref (1.00) & \\
\hline Females & 25 & 15 & 10 & 0 & 40 & 10 & & Ref (1.00) & \\
\hline Allergic (+ve) & 366 & 278 & 83 & 5 & 639 & 93 & 1.5 & $(0.7-3.0)$ & 0.345 \\
\hline Males & 164 & 120 & 42 & 2 & 282 & 46 & 0.7 & $(0.2-2.5)$ & 0.408 \\
\hline Females & 202 & 158 & 41 & 3 & 357 & 47 & 2.4 & $(0.9-6.2)$ & 0.076 \\
\hline
\end{tabular}

A/A, Homozygous Wild; A/B, Heterozygous; B/B, Homozygous Mutant; OR, Odds Ratio; SOB, Shortness of Breath.

However, categorizing the asthma patients on the basis of the phenotypic characteristics of the disease (Table 3), as obtained from their detailed proforma, no significant association was observed between the MBL2 codon $54 \mathrm{~A} / \mathrm{B}$ polymorphism and asthma phenotypes (all $p>0.05$ ).

\section{Discussion}

The present study is the first one to investigate the role of MBL2 codon $54 \mathrm{~A} / \mathrm{B}$ polymorphism in asth- ma propensity in a North Indian population and this research has revealed a highly protective effect of the polymorphism.

The results obtained from the current study supported the above hypothesis with the observations that both the allelic as well as the genotypic frequencies revealed a major role of the functional MBL2 gene in conferring risk towards asthma. In the overall scenario, the wild A allele was more prevalent in the asthma patients $(87.0 \%)$ than in the controls $(78.2 \%)$ in contrast to the mutant B allele which was more prevalent among the control subjects $(21.8 \%)$ than in the asthma patents 
$(13.0 \%)$, indicating an important role of the functional MBL2 gene in asthma pathogenesis, which can well be attributed to the fact that a functional MBL2 gene enhances serum MBL levels. It was also observed that the asthma patients with homozygous wild genotype A/A or with at least one copy of the wild A allele $(\mathrm{A} / \mathrm{A}+\mathrm{A} / \mathrm{B})$ had a significantly increased risk of asthma and were highly predisposed to the disease (Table 2). However, no significant difference in the MBL2 codon 54 allele distributions was found for the phenotypic traits of asthma (all $p>0.05$ ). Further categorizing the nonatopic asthma patients on the basis of gender, neither the non-atopic males nor the females were predisposed to asthma risk.

MBL deficiencies as well as over secretions by the liver in blood have been associated with increased risk, severity, infections and autoimmune disorders [9,24].

Furthermore, in an Indian study conducted on MBL SNPs (816 A/G, 868 C/T, 875 G/A, 884 G/A and 1011 G/A), and Surfactant protein-D (SP-D), it has been observed that MBL $1011 \mathrm{G} / \mathrm{A}$ and SP-D $341 \mathrm{~T} / \mathrm{C}$ polymorphisms were significantly associated with greater risk of atopic asthma [11], while another Indian study has also observed that MBL $1011 \mathrm{G} / \mathrm{A}$ polymorphism resulted in an increased risk for asthma with rhinitis and Allergic Bronchopulmonary Aspergillosis (ABPA) [32].

However, the present study shows completely contrasting results, revealing the predisposing effect of the functional MBL2 codon $54 \mathrm{~A}$ allele as a risk factor for asthma pathogenesis and in contrast a highly protective role of MBL2 codon $54 \mathrm{~A} / \mathrm{B}$ polymorphism in asthma. The results of the present study are supported by various studies wherein high MBL serum levels have been implicated in other non-infectious diseases such as systemic lupus erythematosus (SLE), rheumatoid arthritis, Type-I diabetes, Crohn's disease, cystic fibrosis, sepsis, lung injury, myocardial ischemia-reperfusion as well as asthma $[8,16,20,27,28,35]$. Apart from the involvement in non-infectious diseases, increased MBL levels have also been associated with infectious diseases such as tuberculosis and leprosy [2,29] and it has been suggested that low MBL levels confer protection against TB [12].

Moreover, it has been observed that post allergen challenge, the anaphylatoxin $\mathrm{C} 3 \mathrm{a}$, which is otherwise produced as a byproduct of the MBL pathway, is present in elevated levels in the broncholaveolar lavage (BAL) fluid of asthma patients $[1,10,25,38]$ as well as in the plasma [38], highlighting the role of C3a in MBL pathway. In two separate studies conducted in the USA, it has been observed that the deletion of $\mathrm{C} 3 \mathrm{a}$ receptor in murine models of asthma protects against lung damage observed during allergen challenge during asthma attack, thereby signifying the role of C3a in asthma [1, 33]. Another study has suggested that the complement system not only plays an important role in the innate immunity, but if uncontrolled, contributes to amplified inflammation [19].

Thus, the findings of the present study reveal a protective role of the MBL exon 1 codon $54 \mathrm{~A} / \mathrm{B}$ polymorphism in asthma by offering checkpoints at the MBL as well as the anaphylatoxin production steps in the complement pathway and highlight the major role of the MBL2 codon 54 gene with the functional wild A allele in asthma pathogenesis and suggest that the enhanced serum MBL levels may predispose an individual to asthma by resulting in an increase in the production of pro-inflammatory anaphylatoxins such as $\mathrm{C} 3 \mathrm{a}$ and C5a during the lectin complement pathway.

The role of MBL2 gene polymorphisms in asthma is a much debated scenario. However, the reason for the contrasting results of the studies on MBL2 gene polymorphisms association with asthma obtained in different populations globally can be attributed to the differences in the ethnicities as well as to the complex interplay of the multiple genes and environmental factors involved in the mechanism of asthma pathogenesis.

\section{Acknowledgements}

N. Birbian is highly grateful to Dr. Jagdeep Kaur, Chairperson, Department of Biotechnology, Panjab University, Chandigarh, for her guidance and kind support during the study. The study was supported by research grant from DST, New Delhi (SR/FT/LS-018/ 2008).

\section{References}

[1] A.A. Humbles, B. Lu, C.A. Nilsson, C. Lilly, E. Israel, Y. Fujiwara, N.P. Gerard and C. Gerard, A role for the C3a anaphylatoxin receptor in the effector phase of asthma, Nature 406 (2000), 998-1001.

[2] A. Bonar, M. Chmiela and B. Rozalska, Level of mannosebinding lectin (MBL) in patients with tuberculosis, Pneumonology Alergology Polska 72 (2004), 201-205.

[3] A. Nagy, G.T. Kozma, M. Keszei, A. Treszl, A. Falus and C. Szalai, The development of asthma in children infected with Chlamydia pneumonia is dependent on the modifying effect of mannose-binding lectin, Journal of Allergy and Clinical Immunology 112 (2003), 729-734. 
[4] A. Uguz, Z. Berber, M. Coskun, S. Halide Akbas and O. Yegin, Mannose-binding lectin levels in children with asthma, Pediatric Allergy and Immunology 16 (2005), 231-235.

[5] C.M. Hogaboam, K. Takahashi, R.A. Ezekowitz, S.L. Kunkel and J.M. Schuh, Mannose-binding lectin deficiency alters the development of fungal asthma: effects on airway response, inflammation, and cytokine profile, Journal of Leukocyte Biology 75 (2004), 805-814.

[6] D.C. Kilpatrick, Mannan-binding lectin: clinical significance and applications, Biochimica et biophysica acta 1572 (2002), 401-413.

[7] D.L. Jack, N.J. Klein and M.W. Turner, Mannose-binding lectin: targeting the microbial world for complement attack and opsonophagocytosis, Immunological Reviews 180 (2001), 86-99.

[8] E. Zimmermann-Nielsen, H. Gronbaek, J.F. Dahlerup, G. Baatrup and O. Thorlacius-Ussing, Complement activation capacity in plasma before and during high-dose prednisolone treatment and tapering in exacerbations of Crohn's disease and ulcerative colitis, BMC Gastroenterology 5 (2005), 31.

[9] F. Larsen, H.O. Madsen, R.B. Sim, C. Koch and P. Garred, Disease-associated mutations in human mannose-binding lectin compromise oligomerization and activity of the final protein, Journal of Biological Chemistry 279 (2004), 21302 21311.

[10] F.F. Castro, M. Schmitz-Schumann, U. Rother and M. Kirschfink, Complement activation by house dust: reduced reactivity of serum complement in patients with bronchial asthma, International Archives of Allergy and Applied Immunology 96 (1991), 305-310.

[11] G. Suman Latha, V. Vijayalakshmi, B. Anuradha, V. Hari Sai Priya, S. Kaur, M. Vaid, T. Madan, P.U. Sarma and K.J.R. Murthy, Screening of MBL and SP-D Genes in Indian Population for SNPs and Their Association with Atopic Asthma, International Journal of Human Genetics 6 (2006), 229-232.

[12] H. Cosar, F. Ozkinay, H. Onay, N. Bayram, A.R. Bakiler, M. Anil, D. Can and C. Ozkinay, Low levels of mannose-binding lectin confers protection against tuberculosis in Turkish children, European Journal of Clinical Microbiology \& Infectious Diseases 12 (2008), 1165-1169.

[13] H. Hawlisch, M. Wills-Karp, C.L. Karp and J. Kohl, The anaphylatoxins bridge innate and adaptive immune responses in allergic asthma, Molecular Immunology 41 (2004), 123131.

[14] H.O. Madsen, P. Garred, S. Thiel, J.A. Kurtzhals, L.U. Lamm, L.P. Ryder and A. Svejgaard, Interplay between promoter and structural gene variants control basal serum level of mannanbinding protein, Journal of Immunology 155 (1995), 30133020.

[15] J. Aittoniemi, H. Soranummi, A.T. Rovio, M. Hurme, T. Pessi, M. Nieminen and J. Karjalainen, Mannose-binding lectin 2 (MBL2) gene polymorphism in asthma and atopy among adults, Clinical and Experimental Immunology 142 (2005), $120-124$.

[16] J.E. Jordan, M.C. Montalto and G. Stahl, Inhibition of mannosebinding lectin reduces postischemic myocardial reperfusion injury, Circulation 104 (2001), 1413-1418.

[17] K. Sastry, G.A. Herman, L. Day, E. Deignan, G. Bruns, C.C. Morton and R.A. Ezekowitz, The human mannose-binding protein gene. Exon structure reveals its evolutionary relationship to a human pulmonary surfactant gene and localization to chromosome 10, Journal of Experimental Medicine 170 (1989), 1175-1789.
[18] L. Sompayrac, How the Immune System Works, Blackwell Science: Malden, 1999, pp. 17-19.

[19] M. Abe, Complement activation and inflammation, Rinsho Byori 54 (2006), 744-756.

[20] M.A. Seelen, A. Roos and M.R. Daha, Role of complement in innate and autoimmunity, Journal of Nephrology 18 (2005), 642-653.

[21] M. Matsushita and T. Fujita, Activation of the classical complement pathway by mannose-binding protein in association with a novel C1s-like serine protease, Journal of Experimental Medicine 176 (1992), 1497-1502.

[22] M. Sumiya, M. Super, P. Tabona, R.J. Levinsky, T. Arai, M.W. Turner and J.A Summerfield, Molecular basis of opsonic defect in immunodeficient children, Lancet 337 (1991), 15691570.

[23] M.W. Turner and R.M. Hamvas, Mannose-binding lectin: structure, function, genetics and disease associations, Reviews in Immunogenetics 2 (2000), 305-322.

[24] M.W. Turner, High frequencies in African and non-African populations of independent mutations in the mannose binding protein gene, Human Molecular Genetics 1 (1992), 709-715.

[25] N. Krug, T. Tschernig, V.J. Erpenbeck, J.M. Hohlfeld and J. Kohl, Complement factors C3a and C5a are increased in bronchoalveolar lavage fluid after segmental allergen provocation in subjects with asthma, American Journal of Respiratory and Critical Care Medicine 164 (2001), 1841-1843.

[26] N. Novak and T. Bieber, Allergic and nonallergic forms of atopic diseases, Journal of Allergy and Clinical Immunology 112 (2003), 252-262.

[27] N.P. Gerard and C. Gerard, Complement in allergy and asthma, Current Opinion in Immunology 14 (2002), 705-708.

[28] P. Garred, H.O. Madsen, H. Marquart, T.M. Hansen, S.F. Sorensen, J. Petersen, B. Volck, A. Svejgaard, N.A. Graudal, P.M. Rudd, R.A. Dwek, R.B. Sim and V. Andersen, Twoedged role of mannose binding lectin in rheumatoid arthritis: a cross sectional study, Journal of Rheumatology 27 (2000), 26-34.

[29] P. Garred, M. Harboe, T. Oettinger, C. Koch and A. Svejgaard, Dual role of mannan-binding protein in infections: another case of heterosis? European Journal of Immunogenetics 21 (1994), 125-131.

[30] R.F. Guo and P.A. Ward, Role of C5a in inflammatory responses, Annual Review of Immunology 3 (2005), 821-852.

[31] R.J. Lipscombe, M. Sumiya, A.V. Hill, Y.L. Lau, R.J. Levinsky, J.A. Summerfield and M.W. Turner, High frequencies in African and non-African populations of independent mutations in the mannose binding protein gene, Human Molecular Genetics 1 (1992), 709-715.

[32] S. Kaur, V.K. Gupta, A. Shah, S. Thiel, P.U. Sarma and T. Madan, Elevated levels of mannanbinding leptin (MBL) and eosinophilia in patients of bronchial asthma with allergic rhinitis and allergic bronchopulmonary aspergillosis associate with a novel intronic polymorphism in MBL, Clinical and Experimental Immunology 143 (2006), 414-419.

[33] S.M. Drouin, D.B. Corry, T.J. Hollman, J. Kildsgaard and R.A. Wetsel, Absence of the complement anaphylatoxin C3a receptor suppresses $\mathrm{Th} 2$ effector functions in a murine model of pulmonary allergy, The Journal of Immunology 169 (2002), 5928-5933.

[34] T.F. Leung, N.L. Tang, G.W. Wong and T.F. Fok, CD14 and toll-like receptors: potential contribution of genetic factors and mechanisms to inflammation and allergy, Current Drug targets. Inflammation and Allergy 4 (2005), 169-175. 
[35] T.K. Hansen, L. Tarnow, S. Thiel, R. Steffensen, C.D. Stehouwer, C.G. Schalkwijk, H.H. Parving and A. Flyvbjerg, Association between mannose-binding lectin and vascular complications in type 1 diabetes, Diabetes $\mathbf{5 3}$ (2004), 1570-1576.

[36] W. Cookson, The alliance of genes and environment in asthma and allergy, Nature 402 (1999), 5-11.

[37] X. Wang, J. Saito, Y. Tanino, T. Ishida, T. Fujitaw and M.
Munakata, Mannose binding lectin gene polymorphisms and asthma, Clinical and Experimental Allergy 37 (2007), 13341339.

[38] Y. Nakano, S. Morita, A. Kawamoto, T. Suda, K. Chida and H. Nakamura, Elevated complement $\mathrm{C} 3 \mathrm{a}$ in plasma from patients with severe acute asthma, Journal of Allergy and Clinical Immunology 112 (2003), 525-530. 


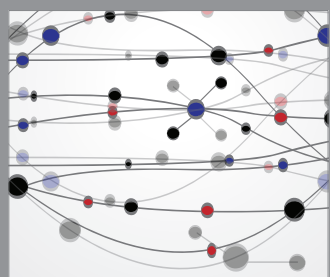

The Scientific World Journal
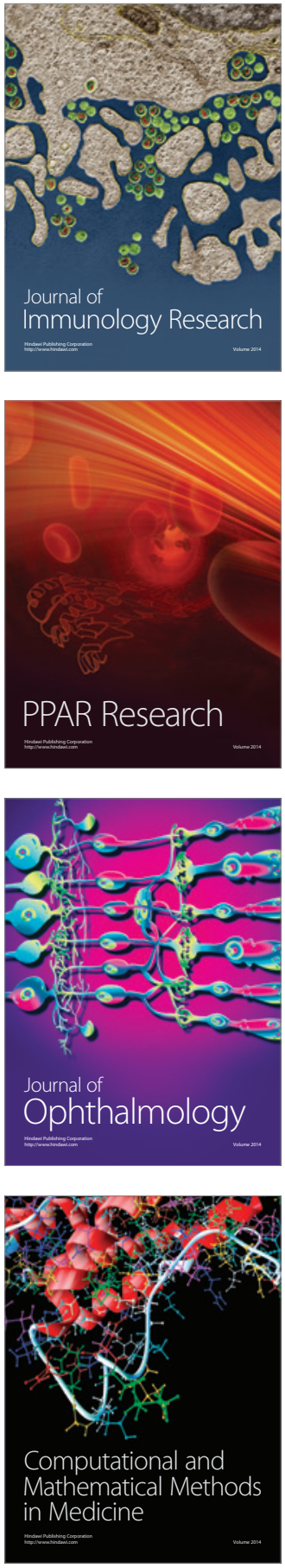

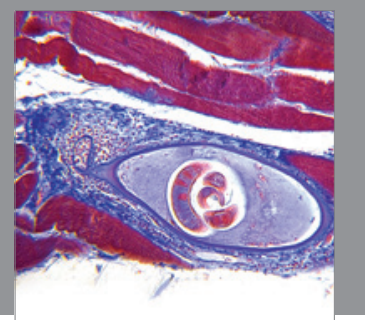

Gastroenterology

Research and Practice
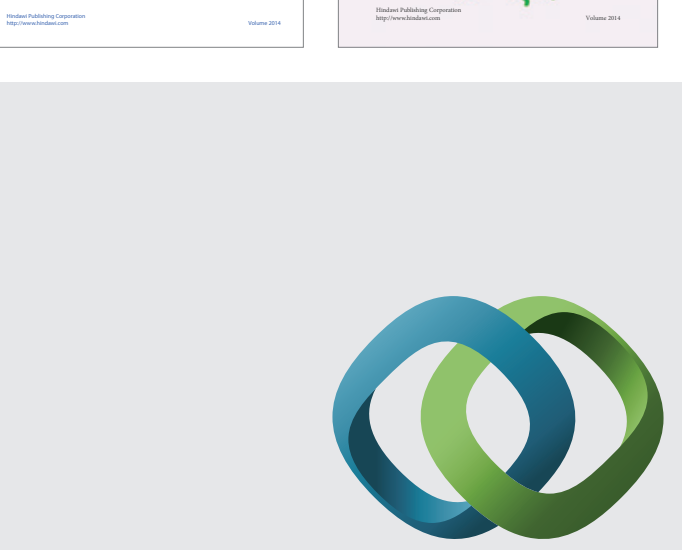

\section{Hindawi}

Submit your manuscripts at

http://www.hindawi.com
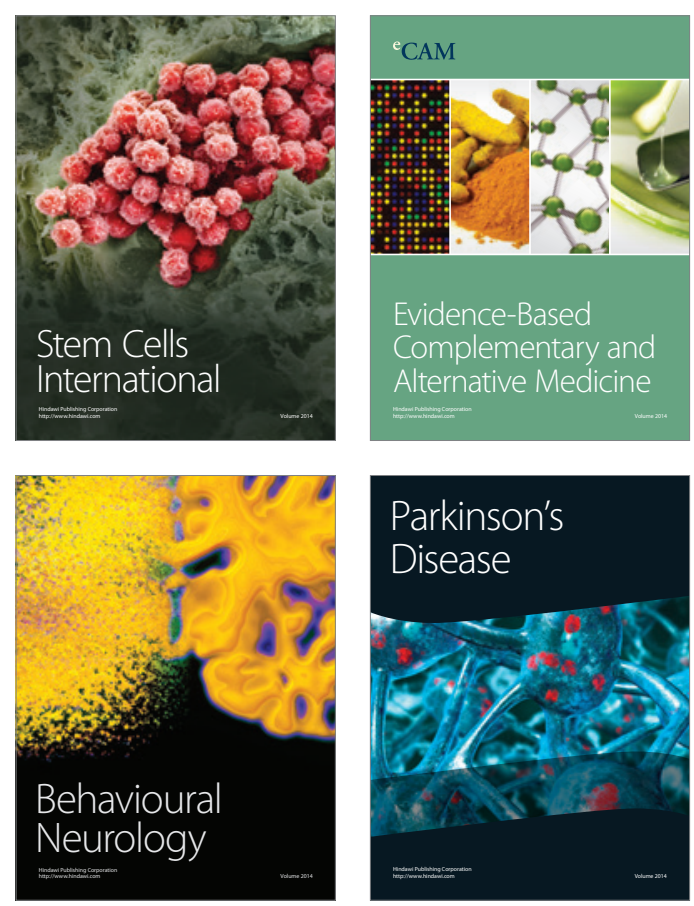

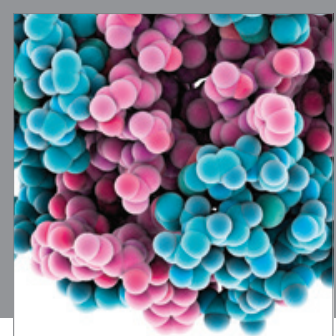

Journal of
Diabetes Research

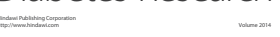

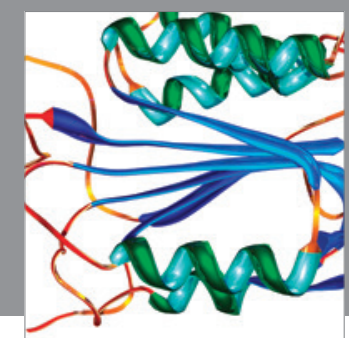

Disease Markers
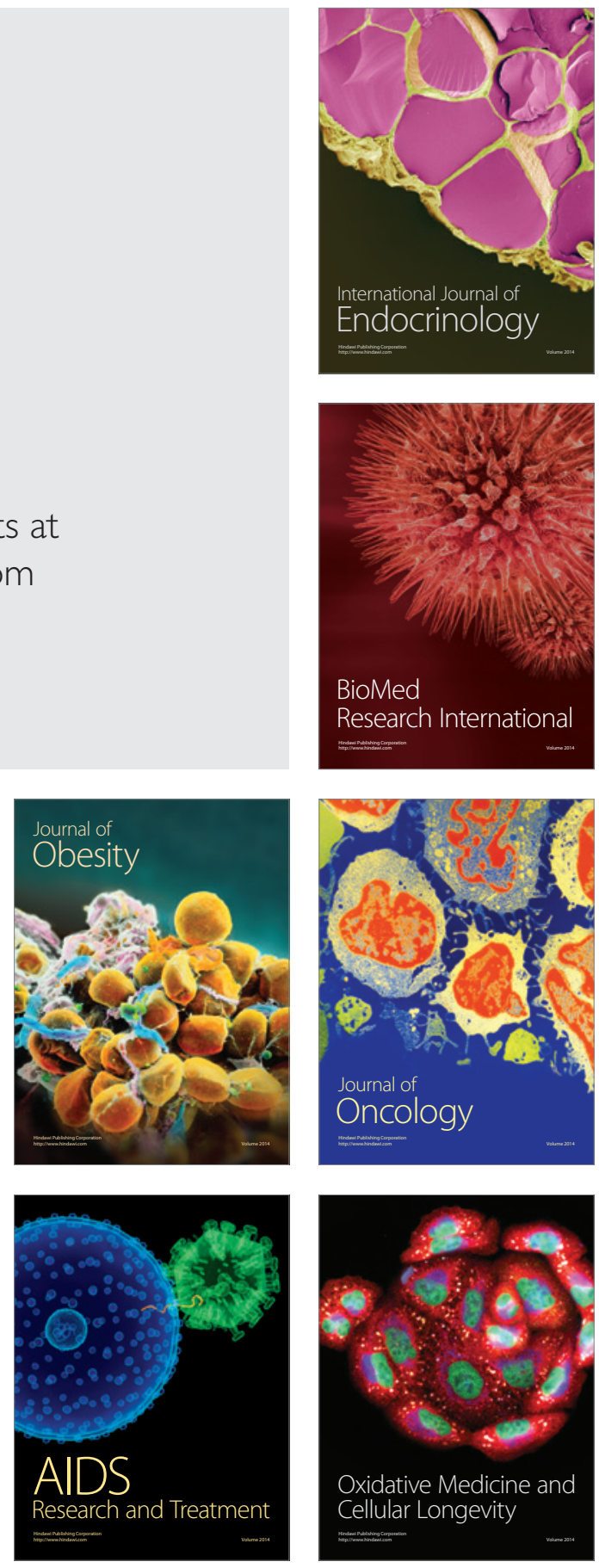